Sankaran, S. \& Dick, B. (2015). Linking theory and practice in project management research using action-oriented methods, in Pasian, B. \& Smit, K. (eds.) Methods, Designs and Practices for Research into Project Management, Gower, Aldershot, U.K., 211-224.

\title{
Linking Theory and Practice in Using Action-Oriented Methods
}

\section{Shankar Sankaran and Bob Dick}

I felt that there is a great opportunity for PM researchers to use dialectical approaches such as action research, action learning and action science to link theory and practice.

The aim of this chapter to provide doctoral students a practical way to use action-oriented methods - action research, action learning and action science - to carry out research in and about projects while making a theoretical contribution to the field. After briefly explaining each of these methods the chapter discusses ways in which these methods can be combined to provide synergy. The chapter discusses some common data collection strategies used with these methods, also pointing out that other methods of data collection are welcome if the research project requires such data. Action research is often criticised for not being scientific and therefore a discussion on how it can be made rigorous and valid at both data collection and data analysis stages is discussed. Action researchers often do not write up their research using the conventions used in conventional quantitative and qualitative research theses or dissertations. A section is therefore devoted to discussing how to write up action research in novel ways. The chapter includes several reflective exercises to guide the reader (student or researcher) as well as some tips for supervisors of action research projects.

At the end of this chapter, the reader can:

- understand the basics of action-oriented methods and how they can be used in a research project;

- justify adequately why action-oriented methods are applicable to your research project;

- establish a model/process to carry out your research applying action-oriented methods.

Keywords: action research, action learning, action science, dialectical approaches 


\section{Characteristics of Action-Oriented Methodologies}

Action research is not a single method or methodology but refers to a variety of approaches that involve working collaboratively with people facing a concern that needs some deliberate action to address it. Such collaboration creates buy-in for implementing the change that accompanies the action. The people who are working together with the action researcher are treated as coresearchers rather than informants. Action research is a cyclical process alternating between action and reflection upon the action to initiate further action converging towards improving the situation of concern.

For more information about various types of action research approaches, refer to the The SAGE handbook of action research (Reason and Bradbury, 2008). In this chapter, we will discuss an action research process that has been found useful in management and organisational research and is used in PM research.

\section{Action Research}

There are several definitions of action research in the literature. This chapter will discuss a few of these to tease out the common characteristics of action-oriented approaches.

The Handbook of action research defines action research as:

a participatory, democratic process concerned with developing practical knowing in the pursuit of worthwhile human purposes, grounded in a participatory worldview which we believe is emerging at this historical moment. It seeks to bring together action and reflection, theory and practice, in participation with others, in the pursuit of practical solutions of pressing concern to people and more generally the flourishing of individual persons and their communities. (Reason and Bradbury, p. 4)

This definition covers a wide variety of approaches under the umbrella of action research. From a PM research point of view, the key features of importance are:

- it is participatory and democratic as well as grounded in a participatory worldview;

- iIt brings together action and reflection;

- it values practical solutions or knowledge that addresses a concern or concern(s);

- it brings together theory and practice; 
- it helps individuals, groups and communities.

For the purposes of this chapter we will use a simpler and more practical definition of action research:

Action research is a flexible spiral process that allows action (change, improvement) and research (understanding, knowledge) to be achieved at the same time. The understanding allows more informed change and at the same time is informed by that change. People affected by the change are usually involved in the action research. This allows the understanding to be widely shared and the change to be pursued with commitment. (Dick, 2001, p 1) See Figure 17.1.

Figure 17.1: Action research process (Dick, 2001, p. 21)

There are similarities between the two definitions. From the latter definition, we can add a few more points about action research.

- it often involves a change or changes to improve the situation;

- $\quad$ action and research happen at the same time;

- people affected by the change are involved in the research that builds commitment;

- the process is not linear but happens in a spiral (improvements happen in a cycle).

While most action research is participatory there may be occasions in which participation could be limited (for example, an organisation in which action research is being conducted does not provide time for participation). This would then relegate the people involved in the research to an informant's role. While action research often happens in cycles, the cycles may not exactly take place exactly as planned and a certain overlap between cycles can be experienced in practice. However, it is good not to skip the reflection phase and resist the temptation to jump into action as managers often do.

\section{Entry and Contracting}

You could be engaged in action research as an external researcher (that is, helping to address a problem that you are not affected by) or as an internal researcher (that is, addressing a problem which affects you as well). In both cases gaining entry and establishing a contract for the research is important. 
As part of the entry and contracting process, it is advisable to identify key stakeholders who are affected by the problem at the start. You would have learnt about stakeholder management applied to projects. You can apply some of these techniques that you have learnt to identify also to your research. Another chapter in this book has dealt with negotiating research sites and access which can provide good ideas about this phase of your research for you to consider.

The stakeholders in an action research situation could be clients (with whom you have contracted to do your research), direct or primary stakeholders who would be affected by your research in some way as well as indirect or secondary stakeholders who have a stake in your research but may not be directly affected by it. As action research involves change and understanding, you may like to separate the stakeholders as supporters and information providers. Your relationship with them is likely to differ based on which group they fall into.

Once you have identified your stakeholders it will be useful to set some time aside to build the appropriate relationship with them prior to contracting. You should continue to build the relationship as you engage in the research activities. As action research is often carried out to take action or achieve outcomes it is good to negotiate the goals of your engagement with the stakeholders as well as your respective roles. This is necessary to build and sustain commitment.

In order to set goals, it may be necessary to conduct some initial investigation with the client and direct stakeholders. This may take the form of interviews or group discussions. This is the stage at which the level of participation can be ascertained and negotiated. This engagement also has the benefit of building relationships for the future. Interviewing each stakeholder provides in-depth information on his or her needs and fears. You should also endeavour to have group discussions to understand group dynamics, which could be important.

With stakeholders who are not directly involved but have an impact on your research you could ask them to appoint representative(s) with whom you can engage. It is best to persuade 
the representative to be actively involved rather than speak for the group of stakeholders they represent when you engage with them.

Action research works best when the research project involves changing a situation with the participants as co-researchers and includes a reflective process as opposed to other approaches that attempt to link theory and practice.

Let us now look at two other action-oriented strategies that were mentioned in the abstract of this chapter.

\section{Action Learning}

Action learning can often be combined with action research when an action research project requires carrying our several embedded projects. These projects also contribute the required data for the research. Later in this chapter we will suggest a model to set up a doctoral research programme where the two can be combined fruitfully.

McGill and Brockbank (2004) define action learning as a 'continuous process of learning and reflection that happens with the support of a group or "set" of colleagues, working on real issues, with the intention of getting things done. The voluntary participants in the group or "set" learn with and from each other and take forward an important issue with the support of the other members of the set' (p. 11).

As the originator of action learning, Reg Revans, who was a physicist, uses the term 'set' and also an equation $\mathrm{L}=\mathrm{P}+\mathrm{Q}$ while describing action learning. In the formula $\mathrm{L}$ is learning, $\mathrm{P}$ is programmed instruction (for example, courses that you attend) and Q is questioning insight (Revans, 1982). Revans strongly suggests that $\mathrm{P}$ is often inadequate to address today's problems as it is based on yesterday's knowledge. He believes that insightful questioning by peers contributes to 90 per cent of learning that occurs during action learning.

To carry out an action learning project you need to work on a problem of mutual concern for a 'set' (normally recommended to be between five to eight members) supported by a 'set adviser' or facilitator. The set advisor's role is to help the set follow the action learning process. 
He/she may have a directive role at the start, becoming less involved as the set gains experience with the process and leave the set if it becomes self-managing.

The action learning set is expected to meet at regular intervals to address problem(s) of the members of the set. For example, if your action learning project is aimed at reducing quality issues in a project, the set would work to find the best way to address this immediately. It will also reflect on why the problem occurred in the first place and recommend processes that would prevent them from occurring in the future.

In an action learning set meeting, there could be one or more 'clients' or 'problem owners' who take responsibility to act on the problem. Sometimes a 'sponsor' is also present during the set meetings. The sponsor is usually someone who has the power or influence to clear obstacles in the path of the 'problem owner'. This is similar to the role we expect of a project sponsor. In an action learning intervention, in which one of the authors was involved, the sponsor was the CEO of the organisation. He was also interested in developing managers to take on senior positions in his organisation through what they learnt through action learning.

When an action learning set meets, usually one or more of the 'problem owners' would explain his/her problem. The other members of the set will ask questions to assist the 'problem owner' to probe his/her problem further. The set members would be asked to avoid asking questions that could provide the solution. Questions in an action learning meeting would be open probing questions to help the problem owner dig deeper. This is often compared to 'peeling an onion'. Sometimes the set members will also deliberately ask challenging questions, when they observe that the 'problem owner' is not thinking deeply enough, in an effort to get the 'problem owner' to reflect and move towards a solution. Towards the end of a set meeting, 'problem owners' will be asked to commit to actions they will undertake before the set meets next. They will also be expected to report on actions in between set meetings.

\section{Action Science}

Action science can be used as part of an action research project or on its own to study one's own practice. This could be useful for a project manager or project team member to improve their 
effectiveness. Action science is a useful strategy for what is known as 'first-person action research as an inquiring approach to his or her own life' (Reason and Bradbury, 2008: p. 6). Action science became prominent by the work carried out by Chris Argyris (Argyris and Schön, 1974, Argyris, Putnam and Smith, 1985). These researchers' aim in developing action science was to find ways to improve professional effectiveness.

Raelin (1997, p. 21) sums up action science by stating that 'people can improve their interpersonal organisational effectiveness by exploring the hidden beliefs that drive their actions'.

According to the website explaining action science (http://www.actionscience.com/actinq.htm\#theory), learning through action science takes place 'when individuals in groups detect and correct gaps between descriptive claims and practical outcomes'. While there is no prescribed process to carry out action science, similar to action learning, there are some basic concepts and tools that can be useful in practising it. The first is to distinguish between 'espoused theory' and 'theory-in-practice’.

Espoused theories are theories that we often think we adopt whereas theory-in-practice are theories that we actually use when faced with a situation involving taking action. Often we are unaware of the difference between our espoused theory and our theory-in-practice. One of the reasons why managers exhibit this incongruence between the two theories is because they are under some threat or embarrassment. We also have governing values that often guide our behaviour. In a recent class that one of the authors taught, the students exhibited defensive behaviour during a negotiation game even after being taught collaborative strategies on negotiating.

Another useful concept in action science is the modelling of theories-in-use. Model 1 theory results in very rational behaviour, focusing on winning and goal achievement and being a 'hero' hiding negative feelings. This could result in mistrust, defensiveness and cause singleloop learning. Single-loop learning forces us maintain the status quo and take actions in line with our Model 1 governing variables. 
When we put Model 2 theory in practice, we are open to information, believe in freedom of choice and commit ourselves to the choices we make. This results in reducing our defensiveness, increasing collaboration and offering a high degree of freedom of choice among other benefits. It also facilitates double-loop learning where we question our goals to accept changing of our governing variables. This would lead to effective problem solving and decision making.

One of the tools useful in action science is the use of a two-column analysis or often called the 'left- and right-hand columns'. To experiment with such an analysis divide a sheet of paper into two columns to write on. On the right-hand column record your observations during a conversation or your interaction with a group (or write it up as a recollection). On the left-hand column record your own thoughts about what is really happening.

\section{Combining Action-Oriented Methods}

While action research, action learning and action science exhibit similarities they are different in some ways. Table 17.1 shows some of the differences if you want to learn more about their philosophical basis and beliefs. Another chapter in the book discusses epistemology and ontology that would be good to refer to when you review Table 17.1. You should take precautions to have the philosophical basis in mind when you apply them together.

Table 17.1 Philosophical basis of action research, action learning and action science (adapted from Raelin, 1999, pp. 120-121)

\begin{tabular}{|l|l|l|l|}
\hline Characteristic & \multicolumn{1}{|c|}{$\begin{array}{c}\text { Action } \\
\text { Research }\end{array}$} & $\begin{array}{c}\text { Action } \\
\text { Learning }\end{array}$ & Action Science \\
\hline Philosophical basis & $\begin{array}{l}\text { Gestalt psychology, } \\
\text { pragmatism, } \\
\text { democracy }\end{array}$ & $\begin{array}{l}\text { Learning from } \\
\text { experience, action } \\
\text { research, and other } \\
\text { eclectic views }\end{array}$ & $\begin{array}{l}\text { Lewinian action } \\
\text { research, Dewey's } \\
\text { theory of inquiry }\end{array}$ \\
\hline Epistemology & $\begin{array}{l}\text { Knowing through } \\
\text { doing and applying } \\
\text { discoveries }\end{array}$ & $\begin{array}{l}\text { Problem solving and } \\
\text { also problem framing }\end{array}$ & $\begin{array}{l}\text { Reflecting-in-action, } \\
\text { making explicit tacit } \\
\text { theories-in-use }\end{array}$ \\
\hline Methodology & $\begin{array}{l}\text { Interactive cycles of } \\
\text { problem defining, } \\
\text { data collection, taking } \\
\text { action or } \\
\text { implementing a }\end{array}$ & $\begin{array}{l}\text { Cycles of framing, } \\
\text { action, reflection, } \\
\text { concluding, and } \\
\text { reframing }\end{array}$ & $\begin{array}{l}\text { Reflection on there- } \\
\text { and-then and here- } \\
\text { and-now reasoning, } \\
\text { with an emphasis on } \\
\text { online interactions }\end{array}$ \\
\hline
\end{tabular}


\begin{tabular}{|l|l|l|}
\hline & $\begin{array}{l}\text { solution, followed by } \\
\text { further testing }\end{array}$ & \\
\hline
\end{tabular}

Vignette - Combining Action-Oriented Approaches in Project Management

Sam was a senior manager of a centre managing global projects in a Japanese multinational company when he enrolled in a $\mathrm{PhD}$ programme. An opportunity to do his research came up when his organisation faced a severe problem that required investigation and action. He decided to use action research as it promised to deliver both management and research outcomes. He wanted to convince his management to use action research to implement change in the way work was being allocated and executed in projects. He was unsure if the management would support using a research methodology. He then learnt about action learning and found that the process had similarities to action research. He also observed that action learning was similar to the kaizen or continuous improvement programmes adopted by the company. So he decided to use action learning principles with a group of managers who were involved in changing the way project work was carried out by the firm.

The reflections from the meetings he had with the action learning set, formed with his managers, became the source of data for his action research project. During the change process, Sam wondered if his managers were actually interested in action learning and not just following his instructions, which reflected the company culture. So he used the left- and right-hand column tool borrowed from action science to examine his use of power during the action learning meetings. This helped him to observe his own model of theory-in-use and the governing values he was using. By reflecting on the outputs of the left- and right-hand column entries he was able to improve the way he managed people. Sam was thus able to use action learning to achieve management outcomes, action research to achieve research outcomes and action science to achieve personal outcomes in his research.

\section{Data Collection Strategies}

There are no set data collection methods that you have to use in an action research project. The methods that you use should fit the type of data you want to collect. Action research generally qualitative uses qualitative methods. Therefore methods used in qualitative research such as 
interviews, observations and focus groups are often used during data collection. It is also not unusual to use quantitative methods if they become necessary.

\section{Vignette: Systems Analyst Using Action Research}

Shirley was a systems analyst who wanted to use action research to improve the way knowledge was used by her organisation. The company had several electronic knowledge-sharing systems in place but employees were found not to use them. She decided to conduct a survey to analyse how information and knowledge was used by employees who were geographically spread out. After analysing the survey using statistical analysis, she found some issues that the employees faced in sharing knowledge via the company's intranet. She then proposed and carried out key projects using an action research approach (in collaboration with key stakeholders) that improved knowledge collection, processing and dissemination in her organisation. Perry and Zuber-Skerritt (1992, p. 204) proposed a model to conduct postgraduate research using action research that has been found useful by several students. One of the authors of this chapter who was investigating management development in his organisation using action research used the model shown in Figure 17.2 adapted from the Perry and Zuber-Skerritt model. In this model the doctoral research process is considered to be the thesis action research cycle. As part of the 'act' phase of the thesis action research, the researcher set up core action learning projects that acted as the source of data for research. The writing of the thesis was also set up as a thesis writing cycle that is informed by the reflections from the thesis action research cycle.

\section{Figure 17.2 Action research model for a doctoral programme (Sankaran, 1999, p. 93)}

While action researchers can use a variety of research methods, we will point out a few that could be particularly useful in action research projects.

\section{Convergent Interviewing}

In a convergent interview, you will have to establish rapport with the informants, just as you would in a normal interview, to make them feel comfortable before introducing yourself and explaining the purpose of the interview. You will also inform who will have access to the information. 
You then ask an opening question to get the informant talking. The question should be quite general to elicit a variety of information. As an example you may say,

I want to know more about the project you are working on right now. I would like to know what you like about working on this project. Is there something you do not like while working on this project?

Get the informant talking for about 30 to 45 minutes and encourage them to talk by affirmations, paraphrasing and seeking more information when they are unclear or drifting. It is important to pay complete attention through active listening.

Towards the end of the interview, you will probe further. The questions that you use for probes should be prepared in advance. They may also be questions that have been prompted by earlier interviews you have conducted. At the end of the interview, it is good to ask the informant to summarise key points they have mentioned.

If it is possible, it is good to pair up with someone else to carry out convergent interviews and share the interviews. Discuss your summaries with each other after you have conducted one interview each. Sampling is very important if you want to increase the rigour of your action research. To ensure a diverse sample try to interview people who you expect to have quite opposing views on the topic. We will discuss why this is important when we discuss rigour in action research later.

\section{Rich Pictures}

Rich pictures, often associated with soft systems methodology, are a way to elicit information about multiple perspectives that stakeholders may have about a problem being investigated.

Rich pictures (situation summaries) are used to depict complicated situations. They are an attempt to encapsulate the real situation through a no-holds-barred, cartoon representation of all the ideas covered already - layout, connections, relationships, influences, cause-and-effect, and so on. One way to use 'rich pictures' in an action research project is to divide your stakeholders into groups (initially into similar groups, for example, same department of an organisation) and ask them to draw a rich picture of a problem of concern. Then ask the different groups to walk 
around to hear an explanation about the issues uncovered by the rich picture. This will help them to appreciate the different views about the situation.

A good book to refer to about the use of soft systems thinking is by Checkland and Poulter (2006) entitled Learning for action: A short definitive account of soft systems methodology and its use for practitioners, teachers and students.

\section{Rigour in Action Research}

Action research is often conducted as qualitative research within an interpretivist paradigm. Therefore, action researchers tend to use techniques recommended to increase validity in qualitative research. A commonly used technique is one suggested by Guba and Lincoln (1985, 1994) to ensure trustworthiness and authenticity. Trustworthiness was proposed as an equivalent to ensuring validity and reliability in quantitative research. This could be achieved by establishing credibility (internal validity), transferability (external validity), dependability (reliability) and confirmability (objectivity). Authenticity, which was added later by Lincoln and Guba (1994) was expected to address political implications from the research. Bryman (2007, p. 414) explains authenticity by elaborating as follows:

- Fairness - Does the research represent different viewpoints of the members in the research setting fairly?

- Ontological authenticity - Does it promote better understanding?

- Educative authenticity - Does it allow multiple perspectives to be understood?

- Catalytic authenticity - Does it motivate members who are participating to engage in action to facilitate change?

- Tactical authenticity - Has it empowered members to take action?

Triangulation is another way of improving validity in qualitative research. One way of achieving triangulation, a metaphor borrowed from navigation, is to use different methods to collect data. Other forms of triangulation include investigator triangulation (recall we suggested 
pairing up on convergent interviews), theoretical triangulation (use of alternate theoretical stance to interpret data) and data triangulation (collecting data from different sources).

When action research is carried out properly, it has several built-in characteristics that can improve rigour - participation that allows collection of richer data; being action-oriented allowing plans to be tested soon after and its responsive and emergent nature. Shorter action cycles also help to increase rigour.

\section{Data Analysis}

The analysis of data in action research will usually match the type of data collected. For example, if you use interviews to collect data you could use content analysis or grounded theory techniques using coding and memos to develop themes.

The main data analysis in action research occurs during the critical reflection phase of an action research cycle. Dick (1999) suggests a way to use multiple data sets to analyse data collected in an action research. Figure 17.3 summarises the process.

\section{Figure 17.3 Analysing data sets in action research}

The basic process is the continuous comparison of data you collect from subsequent interventions and analysing agreements and disagreements between the data sets. If there is agreement look to seek exceptions that can occur and if you find disagreements seek explanations. This could lead to a better understanding and better action in the next cycle.

Silverman (2006) also suggests the use of constant comparison and looking at deviant data (cases or data sets) as a means of increasing the credibility of qualitative research. These can be used in action research to confirm and/or disconfirm findings to increase the rigour.

\section{Writing Up}

Action research theses are often written up in creative and innovative ways without following the conventions suggested for traditional doctoral research theses/dissertations.

The authors have encountered a number of ways in which action research theses have been written up while supervising or examining doctoral theses. Often action research theses are 
written up in the first person as the researcher is deeply involved in the research with the participants. The literature review in action research continues through the research as more literature becomes relevant as the research is carried out. Often the literature is also used as a means of triangulation. Some researchers also write a chapter for each cycle of action research, where the data collected is described, analysed and discussed, instead of having separate data collection, analysis and discussion chapters. It is also common to find a chapter describing the personal learning of the researcher. Often pictures are embedded in the chapters to visually show what went on during the research.

Marshall (2008, pp. 688-693) recommends the following practices in writing about action research:

- $\quad$ accept and seek to express what is rather than what should be;

- employ disciplines and respect emergence;

- $\quad$ invoke the writer in you and your own direct voice, whatever shape it takes;

- create resonant processes and conditions for writing;

- defend emergent form, claim authority;

- $\quad$ value the imagine and metaphorical guides to form.

\section{Tips and Exercises}

Tips for Students

- Read a paper by Kath Fisher and Renata Phelps (2006) titled 'Recipe or performing art? considering challenging conventions for writing action research theses.

- Do a search on the web about search conference or download the paper http://www.elementsuk.com/libraryofarticles/searchconference.pdf. Search for other methods that you might use to bring people together. Do a search on ‘large group intervention' if you are unfamiliar. Or have a look at The change handbook: The definitive resource on today's best methods for engaging whole systems 
by Peggy Holman (2012) or Large group interventions: Engaging the whole system for rapid change by Barbara Bunker and Billie Alban (1997).

- Think about some questions you may ask in an action learning set meeting. How will they be different to the questions you usually ask at your meetings? Check out the website http://www.actionlearningassociates.co.uk/resources/vanbriefing.php to look at some typical questions to ask. Have a look at Action learning for managers by Mike Pedler (2008) or The action learning handbook by Ian McGill and Anne Broadbank (2004). You can also find some resources at the International Foundation of Action Learning site http://ifal.org.uk/.

Tips for Supervisors:

- Action research often does not require a considerable amount of time for upfront reading to find gaps in the literature. A literature review is often required in many universities to confirm candidature. Finding a balance between how much of the literature needs to be reviewed upfront and how much should be read and used during the research needs to be considered.

- Action researchers need to be sceptical about what they find and continuously attempt to disconfirm what they find to increase rigour. So it is good to pose questions to your students when they get excited about what they find.

- You should encourage your students to analyse data as they go rather than pile it up to analyse at the end. This also encourages critical reflection.

- Critically reflection is important. You should encourage your students to develop skills of reflection. Encouraging them to keep a journal or diary and reflect on their own actions during the research could help. Have a look at Questions for critical reflection by Bob Dick [Online]. Available at http://www.scu.edu.au/schools/gcm/ar/arp/reflques.html 
- Encourage your students to think about how they will write up action research. You should, however, caution them about how much latitude examiners may allow.

- Encourage your students to enrol in a course teaching action research where they will have an opportunity to engage with other students. An open-learning programme called AREOL (action research and evaluation online) facilitated by Bob Dick is offered twice a year. See http://www.aral.com.au/areol/areolind.html.

\section{Exercises}

1. Make a list of all the techniques you have read or experienced in conducting an analysis of stakeholders. Do a quick reflection of successful and not so successful engagement with stakeholders. What did you learn from them?

2. At this time, you may also want to think about the types and quality of participation in your engagement. You would have to try and work towards a deep engagement with direct stakeholders (unless circumstances do not allow this). Sometimes, if you have a very large group to deal with, you may have to develop strategies to work with them in small groups periodically. A large group intervention process that can be used to achieve this is a 'search conference'. Search conferences are also recommended in an action research process by Greenwood and Levin (2006).

3. Set up a conversation with someone you are trying to persuade to take some action that is difficult for them. On the right-hand column write down what you said while on the left-hand column write down what you were thinking when you said something. Compare the two after the conversation. What differences did you find? What was your theory-in-use? What governing variable guided your conversation?

For more information about action science have a look at http://www.actionscience.com/actinq.htm\#theory. Read also Values in action: Applying the ideas of Argyris and Schön, by Bob Dick and Tim Dalmau (1999). Take a look at some tools that can help to analyse mental models in Chapter 33 of 
the Fifth discipline fieldbook: Strategies and tools for building a learning organisation by Peter Senge and Associates (1994).

4. Think of a topic you want to conduct a convergent interview about in your own organisation. It would be good if you can find a controversial topic that people are passionate about. Think of an opening question as well as some probe questions you would ask. How will you ensure that you will get a diverse sample?

5. Consider how you will remember the key points from a convergent interview without recording the interview or taking notes as one of the authors of this chapter does. See http://www.mindtools.com/memory.html to develop some techniques for this. This will help you focus better on the interview without being distracted.

\section{References}

Argyris, C. and Schön, D. A. 1974. Theory in practice: Increasing professional effectiveness, San Francisco, CA: Jossey Bass.

Argyris, C., Putnam, R. and Smith, D. 1985. Action science: Concepts, methods, and skills for research and intervention, San Francisco, CA: Jossey-Bass.

Bryman, A. and Bell, E. 2007. Business research methods, 2nd edition, Oxford: Oxford University Press.

Bunker, B. B. and Alban, B. T. 1997. Large group interventions: Engaging the whole system for rapid change, San Francisco, CA: Jossey Bass.

Checkland, P. and Poulter J. 2006, Learning for action: A short definitive account of soft systems methodology and its use for practitioners, teachers and students, Chichester: John Wiley.

Cicmil, S., Williams, T., Thomas, J. and Hodgson, D. 2006. Rethinking project management: Researching the actuality of projects, International Journal of Project Management, 24: 675-686.

Dick, B. 1999. Qualitative action research: Improving the rigour and economy [Online]. Available at http://www.uq.net.au/action_research/arp/rigour2.html. 
Dick, B., 2001. Action research: Action and research, in S. Sankaran, B. Dick, R. Passfield and P. Swepson, Effective change management using action learning and action research: Concepts, frameworks, processes and applications, Lismore, Australia: Southern Cross University Press.

Dick, B. (2002) Action research: Action and research [Online]. Available at http://www.uq.net.au/action_research/arp/aandr.html.

Dick, B. and Dalmau, T. 1999. Values in action: Applying the ideas of Argyris and Schön, Brisbane, Australia: Interchange.

Greenwood, D. J. and Levin, M., 2006. Introduction to action research: Social research for social change, 2nd edition.,Thousand Oaks, CA: Sage.

Guba, E. G. and Lincoln, Y. S., 1985. Naturalistic inquiry, Thousand Oaks, CA: Sage.

Guba, E. G. and Lincoln, Y. S. 1994., Competing paradigms in qualitative research, in N. K. Denzin and Y. S. Lincoln (Eds) Handbook of qualitative research, Thousand Oaks, CA: Sage.

Fisher, K. and Phelps, R. (2006). Recipe or performing art?: Challenging conventions for writing action research theses. Action Research, 4(2): 143-164.

Holman, P., 2012. The change handbook: The definitive resource on today's methods for engaging whole systems, 2nd edition., San Francisco, CA: Berrett Koehler.

Marshall, J. 2008. Finding form in writing for action research, in P. Reason and H. Bradbury (Eds) The SAGE handbook of action research, 2nd edition, London: Sage: pp. 682--694.

McGill, I. and Brockbank, A., 2004. The action learning handbook: Powerful techniques for education, professional development and training, London, Routledge-Farmer.

Pedler, M. 2008. Action learning for managers, Aldershot, UK: Gower.

Perry, C. and Zuber-Skerritt, O. (1992). Action research in graduate management research programs. Higher Education 23: 195-208.

Raelin, J. 1999. Preface, Management Learning, 30(2): 115-126. 
Reason, P. and Bradbury, H., 2008. Introduction, in P. Reason and H. Bradbury (Eds) The SAGE handbook of action research, 2nd edition, London: Sage: pp. 1-10.

Reason, P. and Bradbury, H. (Eds) 2008. The SAGE handbook of action research, 2nd edn, London: Sage.

Revans, R. 1982. The origins and growth of action learning, Bromley, Kent: ChartwellBratt.

Sankaran S., 1999. An action research study of management learning: Developing local engineering managers of a Japanese multinational company in Singapore. PhD Thesis. Adelaide: University of South Australia.

Schön, D. (1983). The reflective practitioner: How professionals think in action, New York: Basic Books.

Senge, P. M., Kleiner, A., Roberts, C., Ross, R. B. and Smith, B. J. 1994. The fifth discipline handbook: Strategies and tools for building a learning organization, London: Nicholas Brealey.

Silverman, D. 2006. Interpreting qualitative data, 3rd edition., London: Sage.

Zuber-Skerritt, O. and Perry, C., 2002 Action research within organisations and university thesis writing, The Learning Organization, 9(4): 171-179. 


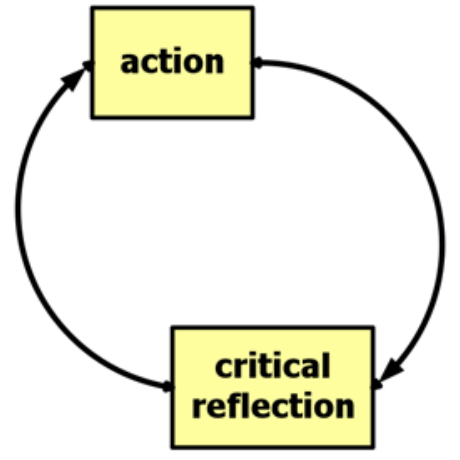

Figure 17.1 Action Research Process (Dick 2001:21) 


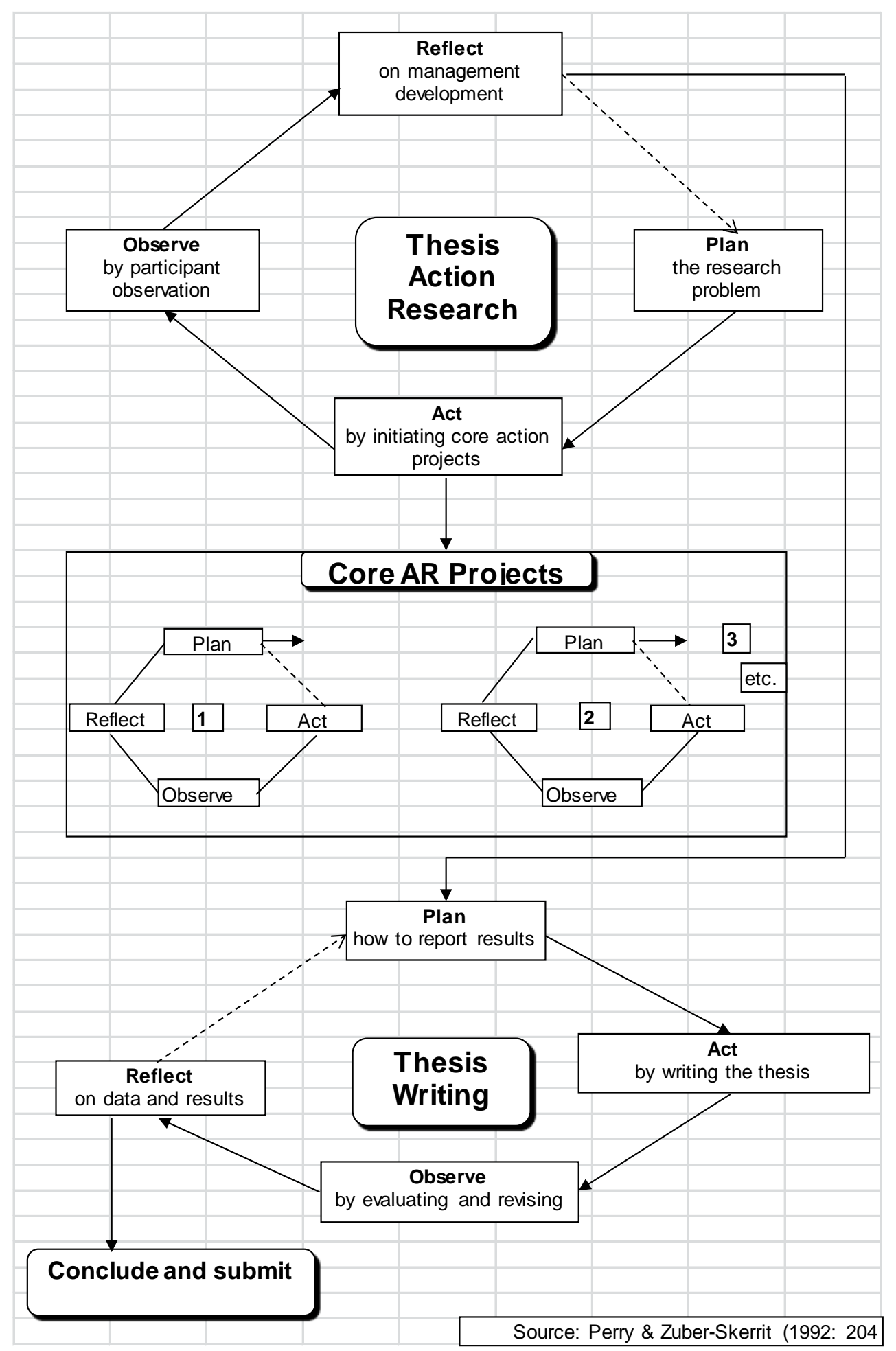

Figure 17.2. - Action Research Model for a Doctoral Program (Sankaran 1999, p.

93) 


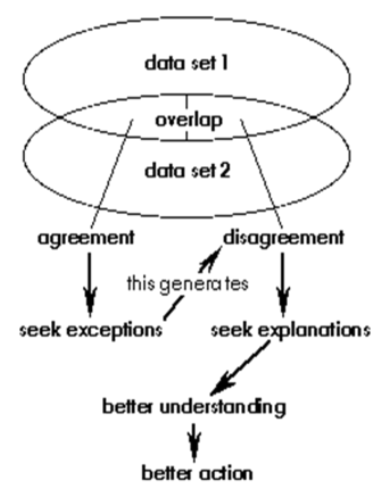

Figure 17.3. - Analysing data sets in action research 